\title{
‘REPORTS GIVEN BY IMAGES’ - FILM AS A CRITICAL MEDIUM FOR ARCHITECTURAL INTERIORITY
}

\author{
CHRISTINE MCCARTHY \\ School of Architecture \\ Victoria University \\ P.O. Box 600, Wellington, New Zealand \\ Christine.mccarthy@vuw.ac.nz
}

\begin{abstract}
"Reality has always been interpreted through the reports given by images" (Sontag 153).

The computer has fast eclipsed manual drawing as the prime source of architectural representation in architectural schools. Studios are relinquishing drawing boards, and students spend long hours in dark computer laboratories, alienated from light and the awareness of passing time. While digital media have opened up new possibilities of experiential, real-time and interactive forms, its new animated form is distinct from the tradition of established moving image narratives, such as film.

The narrative traditions, privileged in conventional computer architecture, frequently render the interior lifeless, objective and emotionally distant. They deny the point of occupation where architectural "circulation" becomes interior design's "lifestyle," and where architectural "durability" is challenged by the surface alterations and changes inflicted by habitation. This is also the point where the volatility of time (as fashion, and the consequences of moving through and living in space) impacts. Time and change are concerns for fashion-conscious interiors rather than for the timelessness stereotypically associated with architecture. It is this particular affinity with time (deformation, wear, fashion) which suggests a critical need for representations of the interior of architecture to assertively engage with time-based and strategically subjective representational media. The paper hence argues a need to assertively deploy film as a representational strategy which actively engages the less measurable aspects of habitation.
\end{abstract}

\section{Introduction}

Giuliana Bruno proposes film as having a "mental itinerary that, finally, makes film the art that is closest to architecture" (24). She argues that "[t]o join the paths of research on architecture and cinema, not optically but haptically, is to corrode oppositions such as immobility-mobility, insideoutside, private-public, dwelling-travel" (24). She sees this space of imagination as an inner landscape, "a trace of inner differences as well as cross-cultural travel" (24).

Bruno's discussion of architecture and film emphasises an interior mental quality. This paper argues that interior architecture, that which engages the inside of buildings as site of habitation, privacy, controlled shelter, vulnerable materiality, and pleasure in the short spans of time 
(fashion, habitation, movement through space, the fading caused by exterior sunlight), is a built environment which has a "natural" affinity to film. It locates the idea of the interior as one of submergence and engagement, as distinct from the exterior as built object, and argues these different conditions thrive more readily on different representational forms. It argues that a representational form which actively engages with the subjective, less measureable aspects of habitation, is a current lack in our representational repertoire, and that such a representational form is critical for the interior of architecture.

\section{Interior Architecture: Interior Design}

Braham, and numerous others, have noted "the strong separation between architecture and interior design" (5). Historically, interior design has been associated with the frivolous, the feminine, the fashionable, the insubstantial and the popular. As Braham states: "those elements that are strong and long-lasting ... are considered masculine and architectural, while those that are short-lived due to wear or fashion ... are assigned to the feminine discipline of interior design" (10). In Bouman's words: "the static nature of architecture, [is] bound up ... with concepts like foundations, durability, inertia and tradition" (64). Issues of interior detail, texture, surface and materiality more constantly occur at a finer scale for interior design than architecture, particularly in student work. The interior as an inside space is subject to mechanisms of control, enabling the ability to transform the exterior environment into an inside able to be manipulated through windows, airconditioning, lighting, and locks on doors, determining its warmth, dryness, appeal for occupation and social climate.

As a discipline, interior design is historically associated with the unregulated amateur or dilettante; the interior designer, or the decorating, or D.I.Y.-ing, inhabitant. It is hence more aligned to the idea of the interior as an explicitly lived and changing space. Interior design's "amateurism" is a trait of its accessibility - "any one" can engage in it. Architecture's knowledge is conventionally considered to be more sacrosanct, and is attained via systems of apprenticeship and university qualification, is often legally regulated and defined. This is conventionally seen to be at odds with informal and unqualified design engagements, stereotyped in the reputed difficulties architects have "When clients move in, inhabit the interior, and start to furnish the house" (Treadwell 286). These "difficulties" are largely within the realm of the interior, as the architectural exterior is much more resistant to change, physically, financially and legally.

It is at the point of occupation that architectural "circulation" becomes interior design's "lifestyle" represented by the surface alterations and changes due to habitation. This is the point where the vulnerability of interior fabrics to the effects of time (as life, fashion, and the wearing consequences of moving through and living in space) occurs. This particular affinity with or engagement with a smaller scale of change and of time suggests a critical need for interior architecture to assertively engage with time-based representational media. The computer and film most immediately propose themselves.

\section{Computer Animation}

Film and computer animation are the most well-known and accessible time-based representational media. Computer animation of architecture has been typified by penz as the "fly-through" (or "fly-by"), and the "walk-through." The "fly-by" is stereotyped as an architectural "boy's toy" where "[m]any animations resort to the techniques of the fly-through in long continuous takes, often plunging at great speed from blue skies to empty streets and to finally penetrate buildings (still at great speed) at the nth floor level" (Penz 106). These seems alien in their distancing strategies of speed and the objectification of building. They often appeal to the exterior, rather than interior representations of architecture, flying around the building to the heavy and unrelenting beat of dance music. Such representations are about speed, objectification and a fleeting, adrenalin-charged architectural engagement. They are a denial of lingering, dwelling or living. This is tourism on a tight schedule, from a speeding airforce jet, and for, it seems, a very specific age and gendered group. This is architecture as industrial design object.

The other extreme in computer animation is the leisurely-paced "walk-through" is more conventionally interested in the interior than the "fly-through." The lineage of the "walk-through" is, at least in part, derived from desire for a virtual guarantee of post-construction architecture, pre-construction. The walk-through is both a substitute "open home," and a device to rearrange the timeline of construction, selling and buying. It is driven by a developer's desire to accelerate, and hence reorder and abbreviate, time, and a formulation of developer priorities in 
architectural relations, devoid of an immediate identification with living and habitation. This lineage enforces the walk-through's rigid narrative of inspection and description which employs a tightly followed, plan-driven circulation of the interior, aiming to provide a sense of even completeness and coherency where everything is seen, giving the viewer a laborious sense of "how spaces relate to one another" (Shaw). This clinging to the logic of the plan also prevents strangers (a visitor, a foreigner, a tourist) becoming lost or disorientated in this usually sterile (often domestic) virtual space. The "walk-through" is a pre-occupation of the uninhabited interior (McCarthy 91-93). It is a sterile display of architecture, typically accompanied by synthetic, elevator music. It turns architecture into a formal, processional experience, a "lifeless computer animation" (Penz 110). This pre-occupation is not a sentimental expectation of habitation as a familiar or an intimate condition. Instead, the experience of the walk-through progresses with the emotional detachments of the property developer's eye which is interested in market value, financial returns and in maximum rentable floor area. These narrative strategies are hence about describing the physical and material manifestation of the interior, and about interiors as vacant and available for occupation. They echo the landscape painting technologies of the nineteenth-century when strategic deployment of pictorial genré, such as the Sublime, conveyed the vacancy (and availability) of land in support of the processes of colonialisation (Ryan 115-117; Pound 19-21).

Unlike computer games, music videos, advertisements, and film, the walk-through is seemingly devoid of emotional investment. The two extremes - of the fly-by and the walk through - are representational forms which privilege architecture as object or as measureable and quantifiable space container. They are without the narrative strategies used in gaming, music videos, advertising and films which make the viewer partial to the habitation of these virtual spaces (through, for example, identification with protagonists, or through aesthetic pleasure). Their apparent objectivity denies a habitation which is about social living, favouring an isolated and mechanised occupation of space. This is a rendering of the interior which is not typically amenable to being a space able to be identified with one's future habitation as a lived phenomenon. As Penz notes: "CAD animations need to be narrated, populated and emotionally expressive" (Penz 111). Representational forms more explicitly imbued with narrative strategies would enable more complex explorations of subjective habitation and temporal change in architecture.

\section{Film}

Film locates the viewer with an invested and manipulated interest. Its representation of interior spaces is partial, fragmented and shaped by the agenda, plot, and spatial narratives of film, rather than the administrative building plan. While some genre make more obvious connections to such statements, many films testing conventional narrative structures construct potent spatial narratives which productively explore interior architecture (e.g. films directed by David Lynch, Matthew Barney). Narrative films most obviously present exchanges between character and setting. The camera is selective and constructs the biased habitat of, for example, the homeowner, the family, the lover, the murderer, the tenant, the thief and the child. The agency and deliberate design of filmic architectural interiors are sutured to the personal agenda of characters with whom the cinema audience identifies, enabling the spaces occupied by these characters to be conceived as conceptually habitable. As Schaal notes: "Film architecture is an architecture of meaning. There is nothing in the frame that is not important and does not have something to say" (16). This construction of space is driven by narrative, plot, and character; filmic perversions of attributes of living and habitation, aspects which are stressed in the production of interior architecture, which have spawned the idea that the interior reflects the character of its occupant, a notion also exploited by film.

The idea of the interior mirroring the occupant has been present in various forms in relation to the architectural interior. Examples include the trend of women of the Aesthetic Movement and the pre-Raphaelites to wear "loose, draping gowns, equating personal adornment with the simpler forms of their new residential interiors" allowed woman's bodies to "fit into their designed surroundings" (McLeod 51, 55). This was not simply a subserviance of the female body to the schema of interior décor, but a more complex oscillating of foreground and background in the casting the female inhabitant and the surfaces of her domestic interior as mutually dependent for significance (McLeod 54-55, 57; Wigley 68, 74, 76). As lonides notes: "To many women the colour of their rooms is only a background for themselves, and since complexion, dress, etc., are considered first with them, the rooms must suit." (73). The matching of clothing to interior surfaces not only matched the female body to décor, but also located the interior surface as susceptible to change. Rosa notes a similar alignment in recent 
Hollywood films where modern domestic architecture "has become identified almost exclusively with characters who are evil, unstable, obsessive and driven by pleasures of the flesh" (159). $\mathrm{He}$ initially traces a tendency in the past practice in film architecture of distinguishing the apartment (young, naive) and the penthouse (wealthy, older, unsentimental, almost never married eccentrics). Modernist houses as "highly seductive sites of crime and deception" are contrasted with conservative/traditional houses and their characters which represent a domestic ideal (Rosa 164).

These injections of "living" narrate occupation into a programme of temporal change, and adaption for architecture, as interior design inflicts narrative through a compulsion of living. As Schwarzer notes of film architecture: "Architecture both contributes to the events taking place among actors and acts independently with other objects in motion and in space. Architecture is protagonist and antagonist, nucleus for the slow collapse of perception into a space between the actors' lines, a visual language with a power all its own." In its disciplinary sense, interior design practice is an activation of interior space as an interactive and narrativised medium. In this sense, film refigures all architecture in terms of conventional interior design concerns. It thus reconstructs and prioritises architecture in terms of time and interacting surface, rather than simply in terms of conventional understandings of space. Architecture in film is interior design. As Schaal notes "Film architecture - interiors and exteriors - is always architecture that has been depicted, photographed, turned into an image. It embraces the actors and scenes like an air-space that has become visible, like a built coat, a petrified robe, a stage set. Its presence defines the setting, the social position of the characters and their inner mood" (16).

Filmic representations of architecture thus produce a time-dependent narrative rather than geospatial contiguity and progression, and in doing so film "documents" the fictive architecture of the interior architectural narrative and separates and distils the geometric logic of plan and architectural form from experiential and ephemeral manifestations. This reconstruction of spatial architecture as temporal, highlights that the significance of discrete and specific architectural spaces is not simply able to be revisited as if they are the same narrative space. Temporal agenda in film redecorate the significance of space in terms of filmic priorities (plot, character, theme). Repetition of filmic space in time, or the temporal adjacency of physically distant spaces (in the film, or as physically built), refigure, manipulate and re-present physical and conventional understandings of architecture. Characterisation, through subjective point of view, also damages assumptions of architecture as consistent, reliable and stable. A child's filmic point of view reveals the volatility perception gives to architecture when contrasted with that of a filmic adult. Architecture becomes interiorised as transient and ephemeral through the disparities of the different points of view of the perceived architectures of floors, walls and ceilings, and demonstrates the different relations and interactions different occupants' experience in the same interior space.

In addition, film, as a representational form, leans towards representing theoretical notions tied to interiority. Critical issues for interior design (such as: habitation, movement, surface, temporality and its disjunction), are wedded to this media which insists on a partiality of representation mimicking the physical constraints of viewing within an enclosed space. Unlike architectural drawings, which often aim to construct an omnipresent eye, film traditionally approximates the subjective and volatile view of the inhabitant. Film also insists on the conversion of the third dimension into time. Space is the third dimension which the film screen flatly refuses, supplying only a serialising two dimensionality as an illusion of three dimensionality, substituting space with time; a four dimensional experience which skips the third dimension. The exchange of time for space shifts the spatial understanding of the interior to having a temporal obligation, a phenomenon which means the camera produces its specific occupation of space through a temporal stitching of two dimensional images: "Space then becomes the animation of these places through the motion of the moving body" (Powell 208). Interior spaces become woven as a fabric of storytelling, and are dependent on the assumption that occupants of plots are also occupants of interior architecture. The film must hence engage with issues of its own media's conventions of representation to unsettle, or disturb these sets of associations with domestic interiority.

Film is a medium which hence understands space as primarily to be an engagement with habitation, while privileging surface and time. As Bruno notes: "She who wanders through a building or a site acts precisely like a film spectator absorbing and connecting visual spaces. The changing position of a body in space creates both architectural and cinematic grounds" (23). This is a complex model of occupation, one both inclusive of, and additional to, pragmatic function. It highlights the possibility of humanity as critical to spatial construction and makes explicit the partial understanding of designed space - the lack of control over the interior, for 
example, after design and construction. It posits interior design as having an investment in the production of unpredictable narrative, not simply to generate space so much as to test the interior which needs negotiate and be altered by it. Film is a medium with a representational tradition which is driven by and assumes change and alteration.

Such a strategy might not be limited to film, but film is a medium which, while it has engaged many architects, is yet to be deployed fully as an important representational force within the architectural education, in particular in reconsidering the potential of the field of interior architecture. Even the most conventional Hollywood films present a radicalisation and theoretical representation of interior architecture as partial, multi-scaled and associated with habitation, and human identity. These are aspects which are not often made explicit in conventional or professional architectural representational forms.

\section{References}

Bouman, O. "Quick Space in Real Time Deel 2." Archis 5 (May 1998):62-65.

Braham, William "A Wall of Books: The Gender of Natural Colors in Modern Architecture." Journal of Architectural Education, 53(1)(1991):4-14.

Bruno, Giuliana "Visual Studies: Four Takes on Spatial Turns." Journal of the Society of Architectural Historians 65(1)(March 2006):23-34.

Bryden, Inga \& Floyd, Janet "Introduction." in Domestic Space: Reading the nineteenth-century interior, ed. Inga Bryden \& Janet Floyd, Manchester and New York: Manchester University Press, 1999:1-17.

Goldstein, Carolyn Do It Yourself: Home Improvement in 20th-Century America New York: Princeton University Press, 1998.

Ionides, Basil Colour and Interior Decoration London: Country Life Ltd; New York: Charles Scribner's Sons, 1926.

McCarthy, Christine "A Barcelona Pavilion" Space and Culture 4/5 (2000):87-98.

McLeod, Mary "Undressing Architecture: fashion, gender and modernity." Architecture, in fashion ed. Deborah Fausch and Paulette Singley, New York: Princeton Architectural Press, 1994:38-123.

Penz, François "Narrating 3D Space." Scroope: Cambridge architecture journal 12 (20002001):106-[111].

Pound, Francis Frames on the Land: Early Landscape Painting in New Zealand Auckland: Collins, 1983.

Rosa, Joseph "Tearing Down the House: modern Homes in the Movies." Architecture and Film ed. Mark Lamster, New York: Princeton Architectural Press, 2000:159-167.

Ryan, Simon The Cartographic Eye: How Explorers saw Australia Cambridge: Cambridge University Press, 1996.

Schaal, Hans Dieter Learning from Hollywood: Architecture and Film Stuttgart; London: Edition Axel Menges, 1996.

Schwarzer, Mitchell "The Consuming Landscape: Architecture in the Films of Michelangelo Antonioni." Architecture and Film ed. Mark Lamster, New York: Princeton Architectural Press, 2000:196-215.

Shaw, James Lecturer in Digital Design, Victoria University, New Zealand, personal communication, 26 January 2005.

Sontag, Susan On Photography London: Penguin Books Ltd, 1979; first published 1977

Treadwell, Sarah "From the margins of architecture; an account of domestic chaos" New Dreamland: Writing New Zealand Architecture ed. Douglas Lloyd Jenkins, Auckland: Godwit, 2005:284-297.

Vidler, Anthony The Architectural Uncanny: essays in the modern unhomely Cambridge, Massachusetts: MIT Press, 1999.

Wigley, Mark White Walls, Designer Dresses: The Fashioning of Modern Architecture Cambridge, Massachusetts: MIT Press, 1995. 